\title{
Racial/ethnic differences in the prevalence and incidence of metabolic syndrome in high-income countries: a protocol for a systematic review
}

Nicholas Kofi Adjei ${ }^{1,2^{*}}$, Florence Samkange-Zeeb ${ }^{1}$, Mihiretu Kebede ${ }^{1,2}$, Maham Saleem¹, Thomas L. Heise ${ }^{1,2}$ and Hajo Zeeb ${ }^{1,2}$

\begin{abstract}
Background: Metabolic syndrome is a constellation of various cardiovascular and type 2 diabetes risk factors, such as abdominal obesity, atherogenic dyslipidemia, high blood pressure, and high blood glucose, but its prevalence varies widely by geographical region, sex, and race/ethnicity. The objective of this study is to examine the prevalence and incidence of metabolic syndrome among adults of different racial/ethnic origins in high-income countries.

Methods: We designed and registered a study protocol for a systematic review of descriptive epidemiological data. Observational studies (e.g., cross sectional and cohort studies) reporting morbidity data of metabolic syndrome and conducted in a wide range of adult people (e.g., different racial/ethnic origins, including migrants) will be included. The primary outcome will be the prevalence and incidence of metabolic syndrome. Secondary outcomes will be the prevalence and incidence of individual components of metabolic syndrome (e.g., abdominal obesity, dyslipidemia, high blood pressure, and high blood glucose). Literature searches will be conducted in several electronic databases (from inception onwards), including MEDLINE, Web of Science Core Collection (Science Citation Index and Social Science Citation Index), CINAHL, and Cochrane Library. Two investigators will independently screen all reference titles, abstracts, and full-text articles. The methodological quality (or potential bias) of selected studies will be appraised using an appropriate tool. Our results will be described narratively. Random-effects meta-analysis will be conducted, if feasible and appropriate. Additional analyses will be conducted to explore the potential sources of heterogeneity.

Conclusion: This systematic review will identify, evaluate, and integrate prevalence and incidence data of metabolic syndrome, with focus on racial/ethnic differences in high-income countries. We anticipate our findings may guide policy formulation and identify knowledge gaps in the literature that future research should address.
\end{abstract}

Systematic review registration: PROSPERO, CRD42020157189

Keywords: Metabolic syndrome (MetS), Race, Ethnicity, Migrants, High-income countries

\footnotetext{
* Correspondence: adjei@uni-bremen.de

'Department of Prevention and Evaluation, Leibniz Institute for Prevention

Research and Epidemiology - BIPS, Achterstrasse 30, D-28359 Bremen, Germany

${ }^{2}$ Health Sciences Bremen, University of Bremen, Bremen, Germany
}

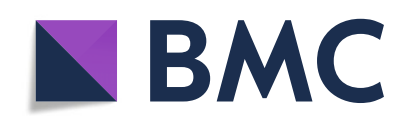

(- The Author(s). 2020 Open Access This article is licensed under a Creative Commons Attribution 4.0 International License, which permits use, sharing, adaptation, distribution and reproduction in any medium or format, as long as you give appropriate credit to the original author(s) and the source, provide a link to the Creative Commons licence, and indicate if changes were made. The images or other third party material in this article are included in the article's Creative Commons licence, unless indicated otherwise in a credit line to the material. If material is not included in the article's Creative Commons licence and your intended use is not permitted by statutory regulation or exceeds the permitted use, you will need to obtain permission directly from the copyright holder. To view a copy of this licence, visit http://creativecommons.org/licenses/by/4.0/. The Creative Commons Public Domain Dedication waiver (http://creativecommons.org/publicdomain/zero/1.0/) applies to the data made available in this article, unless otherwise stated in a credit line to the data. 


\section{Background}

Metabolic syndrome (MetS) is a clustering of metabolic and physiological abnormalities [1], including hyperglycemia, obesity, atherogenic dyslipidemia, and hypertension $[1,2]$. As MetS is not a single pathogenic entity, but rather an array of risk factors for cardiovascular and metabolic diseases [3, 4], various institutions have defined it differently [5-7]. Among these institutions are the World Health Organization (WHO) [8], International Diabetes Federation (IDF) [6], National Cholesterol Education Program Adult Treatment Panel III (NCEP: ATPIII) [9], and the American Heart Association/National Heart, Lung and Blood Institute (AHA/NLHBI) [5]. There are but some minor variations in the definitions of MetS proposed by the named institutions [6]. At present, the two most widely used definitions are those put forward by the NCEP: ATPIII and the IDF [10].

The worldwide prevalence of MetS among adults is estimated to be $20-25 \%$ [11], but there are country and regional variations [12] depending on the definitions used [10]. The National Health and Nutrition Examination Survey (NHANES) in the USA estimated the prevalence of MetS to be $34.5 \%$, based on the NCEP: ATPIII criteria [13]. Australia has a prevalence of $22.1 \%$ using the NCEP: ATPIII definition and $30.7 \%$ using the IDF definition [14]. In Europe, the overall prevalence has been reported to be 24.3\% according to the NCEP: ATPIII definition [15].

There is however evidence that the prevalence and incidence of MetS differ between specific populations (i.e., by sex, race, and ethnicity) in high-income countries [13, 16]. Previous studies in Europe suggest a higher prevalence of MetS among migrants/ethnic minorities than host populations [17]. In the USA, some racial/ethnic differences have also been noted $[18,19]$. Whereas some studies reported higher prevalence of MetS in nonHispanic Whites compared to Black populations [20, 21 , other findings suggest that Hispanics are at an increased risk of developing MetS than non-Hispanic Whites [22, 23]. The patterning of these inequalities are complex, and several studies implicate genetic variation, environmental and socio-economic factors as contributing factors to the possible causes of racial/ethnic differences in cardiovascular and metabolic diseases [24, 25]. A better understanding of MetS prevalence and incidence among diverse racial/ethnic groups is crucial for the inequalities in metabolic diseases to be addressed.

The objective of this study will be to systematically evaluate observational epidemiological studies that present prevalence and incidence data of metabolic syndrome among adults of different racial/ethnic groups. The research question that will be addressed is - to what extent do incidence and prevalence of metabolic syndrome differ among racial/ethnic groups of adults in high-income countries?

\section{Methods}

The present protocol has been registered within the PROSPERO database (Registration ID: CRD42020157189). This study protocol is being reported in accordance with the reporting guidance provided in the Preferred Reporting Items for Systematic Reviews and Meta-Analyses Protocols (PRISMA-P) statement [26] (see PRISMA-P checklist in Additional file 1). The proposed systematic review will be reported in accordance with the reporting guidance provided in the Preferred Reporting Items for Systematic Reviews and Meta-analyses (PRISMA) statement [27] and the Meta-analysis Of Observational Studies in Epidemiology (MOOSE) reporting guideline [28].

\section{Inclusion and exclusion criteria}

Studies will be selected according to the following criteria: study design (and context), participants, exposures, and condition or outcome(s) of interest.

\section{Study design and context}

Eligible studies will be quantitative, observational studies (cohort, cross-sectional or health surveys) reporting prevalence and/or incidence data using validated and non-validated tools and conducted in a wide range of people in the general, non-institutionalized population (e.g., including data from administrative databases and registries) from high-income countries. Cross-sectional studies will be the most appropriate study design to determine the prevalence of metabolic syndrome, and cohort studies will be the most appropriate study design to determine the incidence of metabolic syndrome. Crosssectional health surveys are typically used to estimate the point prevalence of common conditions of long duration. For cohort studies, both the first phase (cross sectional) data and follow-up phase will be considered. We will exclude studies in hospital/inpatient clinical settings because they are likely to be highly selected (selection bias), resulting in inaccurate estimations of the "true prevalence and incidence" of the metabolic syndrome across different groups in the general population. In addition, we will exclude reviews, case reports, case series, qualitative studies, and opinion articles. However, we will use review articles to identify any potential studies that might have been missed from our search.

\section{Participant (population)}

We will include studies involving adult populations $(\geq 18$ years old), regardless of sex and race/ethnicity in highincome countries, as classified by the Organization for Economic Co-operation and Development (OECD) [29]. 


\section{Exposures and comparators}

The main exposure in this study will be race/ethnicity and immigration status. We will define a priori the following racial/ethnic groups [e.g., White/European, Hispanic/Latin American, Black/African (e.g., Sub-Saharan African and Caribbean), Asian, and Arab]. Studies in a homogeneous population with diverse tribal groups will be excluded. Studies comparing migrants and host populations will be included. Since there is heterogeneity in how migrants are labeled, we will follow the general conventions used globally [30]. In studies reporting comparisons between racial/ethnic groups, the comparator will be the "majority" groups. For example, in the USA, the majority ethnic group would be "White," while the minority ethnic group would be "Black" "Hispanic" "Asian," and "other" ethnic backgrounds [31]. In Europe, the minority ethnic group will generally also include people with a migration background [32].

\section{Outcomes}

The primary outcome will be the prevalence and incidence of metabolic syndrome. We will use authorreported definitions (according to accepted diagnostic criteria, but also self-reported). According to the harmonized definition [33], diagnosis of metabolic syndrome requires the fulfillment of at least 3 of the following 5 criteria: waist circumference $\geq 102 \mathrm{~cm}$ in men and $\geq 88 \mathrm{~cm}$ in women; fasting blood glucose level $\geq 100 \mathrm{mg} / \mathrm{dL}$ or treatment with antidiabetic drugs; systolic or diastolic blood pressure $\geq$ $130 \mathrm{mmHg}$ or $\geq 85 \mathrm{mmHg}$, respectively, or treatment with antihypertensive medication; triglyceride level $\geq 150 \mathrm{mg} /$ $\mathrm{dL}$; and serum high-density lipoprotein cholesterol level < $40 \mathrm{mg} / \mathrm{dL}$ in men or $<50 \mathrm{mg} / \mathrm{dL}$ in women.

Secondary outcomes will be the prevalence and incidence of individual components of metabolic syndrome, such as abdominal obesity, dyslipidemia, high blood pressure, and high blood glucose.

\section{Information sources and search strategy}

The primary source of the literature will be a structured search of major electronic databases (from inception onwards): MEDLINE (Ovid), Web of Science Core Collection (the Social Science Citation Index [SSCI], the Science Citation Index $[\mathrm{SCI}]$ ), the Cumulative Index to Nursing and Allied Health Literature (CINAHL), and Cochrane Library. We will also perform hand-searches of the reference lists of included studies, relevant reviews, clinical practice guidelines or other relevant documents. Further, content experts and authors who are prolific in the field will be contacted. The literature searches will be designed and conducted by the review team with the help of a health information specialist. A draft search strategy for MEDLINE is provided in Additional file 2. No limitations will be imposed on language, publication status, and study conduct period. The search results will be uploaded to an online reference management tool (EndNote X9.2 reference manager).

\section{Screening and selection of studies}

All references identified from the literature search will be imported into Covidence [34], a web-based software that aids the management of systematic reviews. This software will further be used for the title/abstract screening. First, titles and abstracts of references returned from initial searches will be screened independently by two reviewers (NKA and FSZ), based on the eligibility criteria outlined above. Second, full texts will be examined in detail and screened for eligibility by the two reviewers. Third, the references of all the included studies will be hand-searched to identify any relevant report missed in the initial searches. Any disagreements between the two reviewers will be resolved by discussion to meet a consensus. A flow chart showing details of studies included and excluded at each stage of the study selection process will be provided.

\section{Data extraction}

Data extraction will be done independently by the two reviewers (NKA and FSZ), in a pre-piloted data extraction form created in MS Excel. Any discrepancies in the extracted data will be resolved by consensus or discussion with a third reviewer (HZ). The following details will be extracted from each study: (i) details of the study (first author's last name, year of publication, country), (ii) study design (study design, sample size, sampling method, ethnic group, age, and gender of participants), (iii) metabolic syndrome definition criteria, (iv) frequency, incidence, and prevalence of metabolic syndrome and its components for all adults.

\section{Quality assessment and risk of bias}

The risk of bias in the included studies will be assessed by two review authors (NKA and FSZ), using the Effective Public Health Practice Project (EPHPP) assessment tool for quantitative studies [35]. The EPHPP assess different components of study validity: study design, confounders, selection bias, blinding, data collection method, and dropouts. The overall methodological quality will be rated as strong, moderate or weak. A third reviewer (HZ) will be consulted should there be differences in opinion.

\section{Data synthesis and analysis}

The data from each study (i.e., prevalence and incidence) will be used to construct evidence tables of an overall description of the included studies. If the studies are diverse and quantitative syntheses is not feasible, we will consider presenting the reported studies using albatross plots, following the methodological guideline by Harrison and colleagues [36]. Heterogeneity across studies 
with respect to characteristics of studies such as design, population, and methodological difference will first be qualitatively evaluated. Secondly, statistical heterogeneity will be quantified using I-square and Tau-square statistics. Cochrane chi-square test will be used to evaluate statistical heterogeneity at $10 \%$ level of significance. If meta-analysis is feasible and studies are found to be combinable, random-effects meta-analysis of prevalence/ incidence data will be conducted for primary and secondary outcomes. We anticipate a sizable statistical heterogeneity across studies; hence, we will estimate the pooled prevalence using the random-effects model. If sufficient studies are identified and data points are available, we will investigate potential sources of heterogeneity, and forest plots will be used to visualize the extent of heterogeneity among studies. We plan to conduct subgroup analysis by gender (male vs. female).

\section{Meta-biases}

If the data permits, publication bias across individual studies will be assessed by visually inspecting the asymmetry track pattern on the funnel plot and by Egger's test [37]. In addition, the impact of risk of bias of individual studies on the overall effect size will be assessed by conducting meta-regression and subgroup analysis. We will compare pooled effect sizes for subgroup of studies (i.e., studies with high risk of bias vs low risk of bias).

\section{Discussion}

MetS and its components, namely, central obesity, raised blood pressure, hyperglycemia, and dyslipidemia [1, 2, 38] have been identified as risk factors for type 2 diabetes [39, 40], cardiovascular diseases [3], and coronary heart disease-related mortality [41]. To our knowledge, this will be the first review to systematically synthesize and collate the available evidence on the incidence of prevalence of MetS in different racial/ethnic groups, including migrant populations. The results will provide an opportunity for interventions to avert the development of cardiovascular diseases among certain racial/ethnic groups [42], especially ethnic minorities [32]. The findings may further guide policy formulation and also highlight gaps in the literature that need to be considered in future research. The review findings will be made publicly available, thus any amendment made to this protocol will be outlined and reported in the final manuscript and the PROSPERO database.

The proposed study may have some limitations at the study and review level, inter alia, expected heterogeneity in the individual studies, quality of the study designs and definition, and assessment of the primary outcome.

\section{Supplementary information}

Supplementary information accompanies this paper at https://doi.org/10. 1186/s13643-020-01400-y.

Additional file 1:. PRIMA-P 2015 checklist

Additional file 2:. Medline Search strategy

\begin{abstract}
Abbreviations
CINAHL: Cumulative Index to Nursing and Allied Health Literature; EPHPP: Effective public health practice Project; IDF: International Diabetes Federation; MetS: Metabolic syndrome; NCEP: ATPIII: National Cholesterol Education Program Adult Treatment Panel III; NHANES: National Health and Nutrition Examination Survey; OECD: Organization for Economic Cooperation and Development; PRISMA: Preferred Reporting Items for Systematic Reviews and Meta-Analyes; SCl: Science citation index; SSCl: Social science citation index; WHO: World Health Organization
\end{abstract}

\section{Acknowledgements}

The authors would like to acknowledge the help of Ms. Lara Christianson for selecting appropriate databases and compiling search items for this study.

\section{Authors' contributions}

NKA and $\mathrm{HZ}$ conceived the initial idea for the study. NKA wrote the protocol with input from MS. NKA, HZ, MS, FSZ, MK, and TH critically appraised the protocol manuscript. NKA will act as a first reviewer, and MS, FSZ, MK, and $\mathrm{TH}$ will act as second reviewers in the review. All authors approved the final version of the manuscript.

\section{Funding}

This work was supported by the Leibniz Institute for Prevention Research and Epidemiology - BIPS, Germany Intramural Research Fund.

Availability of data and materials

Not applicable

Ethics approval and consent to participate

Not applicable

Consent for publication

Not applicable

Competing interests

The authors declare that they have no competing interests.

Received: 30 December 2019 Accepted: 27 May 2020

Published online: 08 June 2020

References

1. Alberti KGM, Zimmet P, Shaw J. The metabolic syndrome-a new worldwide definition. Lancet. 2005;366(9491):1059-62.

2. Grundy SM, Cleeman JI, Daniels SR, Donato KA, Eckel RH, Franklin BA, et al. Diagnosis and management of the metabolic syndrome: an American Heart Association/National Heart, Lung, and Blood Institute scientific statement. Circulation. 2005;112(17):2735-52.

3. Galassi A, Reynolds K, He J. Metabolic syndrome and risk of cardiovascular disease: a meta-analysis. Am J Med. 2006;119(10):812-9.

4. Mottillo S, Filion KB, Genest J, Joseph L, Pilote L, Poirier P, et al. The metabolic syndrome and cardiovascular risk: a systematic review and metaanalysis. J Am Coll Cardiol. 2010;56(14):1113-32.

5. Grundy S. American heart association; national heart, lung, and blood institute. Diagnosis and management of the metabolic syndrome: an American heart association/national heart, lung, and blood institute scientific statement. Circulation. 2005;112:2735-52.

6. Alberti KGMM, Zimmet P, Shaw J. Metabolic syndrome-a new world-wide definition. A consensus statement from the international diabetes federation. Diabet Med. 2006:23(5):469-80.

7. Balkau B. Comment on the provisional report from the WHO consultation. European Group for the Study of Insulin Resistance (EGIR). Diabet Med. 1999;16: $442-3$. 
8. Alberti KGMM, Zimmet PZ. Definition, diagnosis and classification of diabetes mellitus and its complications. Part 1: diagnosis and classification of diabetes mellitus. Provisional report of a WHO consultation. Diabet Med. 1998;15(7):539-53.

9. National Institutes of Health. Third report of the National Cholesterol Education Program (NCEP) Expert Panel on detection, evaluation, and treatment of high blood cholesterol in adults (Adult Treatment Panel III): International Medical Pub; 2002

10. Kassi E, Pervanidou P, Kaltsas G, Chrousos G. Metabolic syndrome: definitions and controversies. BMC Med. 2011;9(1):48.

11. Mulder RL, Bresters D, Van den Hof M, Koot BG, Castellino SM, Loke YKK, et al. Hepatic late adverse effects after antineoplastic treatment for childhood cancer. Cochrane Database Syst Rev. 2019;4:CD008205.

12. Cameron AJ, Shaw JE, Zimmet PZ. The metabolic syndrome: prevalence in worldwide populations. Endocrinol Metab Clin. 2004;33(2):351-75.

13. Ford ES. Prevalence of the metabolic syndrome defined by the International Diabetes Federation among adults in the US. Diabetes Care. 2005;28(11):2745-9.

14. Cameron AJ, Magliano DJ, Zimmet PZ, Welborn T, Shaw JE. The metabolic syndrome in Australia: prevalence using four definitions. Diabetes Res Clin Pract. 2007;77(3):471-8.

15. Scuteri A, Laurent S, Cucca F, Cockcroft J, Cunha PG, Mañas LR, et al. Metabolic syndrome across Europe: different clusters of risk factors. Eur J Prev Cardiol. 2015;22(4):486-91.

16. Rampal S, Mahadeva S, Guallar E, Bulgiba A, Mohamed R, Rahmat R, et al. Ethnic differences in the prevalence of metabolic syndrome: results from a multi-ethnic population-based survey in Malaysia. PLoS One. 2012;7(9): e46365.

17. van der Linden EL, Meeks K, Beune E, de Graft Aikins A, Addo J, OwusuDabo E, et al. The prevalence of metabolic syndrome among Ghanaian migrants and their homeland counterparts: the research on obesity and type 2 diabetes among African migrants (RODAM) study. European Journal of Public Health. 2019

18. Beltrán-Sánchez H, Harhay MO, Harhay MM, McElligott S. Prevalence and trends of metabolic syndrome in the adult US population, 1999-2010. J Am Coll Cardiol. 2013;62(8):697-703.

19. Ford ES, Giles WH, Dietz WH. Prevalence of the metabolic syndrome among US adults: findings from the third National Health and Nutrition Examination Survey. Jama. 2002;287(3):356-9.

20. Marcotte-Chénard A, Deshayes TA, Ghachem A, Brochu M. Prevalence of the metabolic syndrome between 1999 and 2014 in the United States adult population and the impact of the 2007-2008 recession: an NHANES study. Appl Physiol Nutr Metab. 2019;44(8):861-8.

21. Palaniappan L, Carnethon MR, Wang Y, Hanley AJ, Fortmann SP, Haffner SM et al. Predictors of the incident metabolic syndrome in adults: the insulin resistance atherosclerosis study. Diabetes Care. 2004;27(3):788-93.

22. Boden-Albala B, Sacco RL, Lee HS, Grahame-Clarke C, Rundek T, Elkind MV et al. Metabolic syndrome and ischemic stroke risk: Northern Manhattan study. Stroke. 2008;39(1):30-5

23. Fruge AD, Byrd SH, Fountain BJ, Cossman JS, Schilling MW, Gerard P. Race and gender disparities in nutrient intake are not related to metabolic syndrome in 20- to 59-year-old US adults. Metab. 2014;12(8):430-6.

24. McKeigue PM. Mapping genes underlying ethnic differences in disease risk by linkage disequilibrium in recently admixed populations. Am J Hum Genet. 1997;60(1):188.

25. Nazroo JY. Genetic, cultural or socio-economic vulnerability? Explaining ethnic inequalities in health. Sociology of Health \& IIIness. 1998;20(5):710-30.

26. Moher D, Shamseer L, Clarke M, Ghersi D, Liberati A, Petticrew M, et al. Preferred reporting items for systematic review and meta-analysis protocols (PRISMA-P) 2015 statement. Systematic reviews. 2015;4(1):1.

27. Moher D, Liberati A, Tetzlaff J, Altman DG. Preferred reporting items for systematic reviews and meta-analyses: the PRISMA statement. Ann Intern Med. 2009:151(4):264-9.

28. Stroup DF, Berlin JA, Morton SC, Olkin I, Williamson GD, Rennie D, et al. Meta-analysis of observational studies in epidemiology: a proposal for reporting. Jama. 2000;283(15):2008-12.

29. Woodward R. The organisation for economic co-operation and development (OECD): Routledge; 2009.

30. Urquia ML, Gagnon AJ. Glossary: migration and health. J Epidemiol Community Health. 2011;65(5):467-72.

31. Yanow D. Constructing race and ethnicity in America: category-making in public policy and administration: Routledge; 2015.
32. Linden ELvd, Meeks K, Beune E, Aikins Ad-G, Addo J, Owusu-Dabo E, et al. The prevalence of metabolic syndrome among Ghanaian migrants and their homeland counterparts: the research on obesity and type 2 diabetes among African migrants (RODAM) study. Eur J Pub Health 2019;29(5):906-913.

33. Alberti K, Eckel R, Grundy S, Zimmet P, Cleeman J, Donato K, et al. A joint interim statement of the International Diabetes Federation Task Force on Epidemiology and Prevention; National Heart, Lung, and Blood Institute; American Heart Association; World Heart Federation; International Atherosclerosis Society; and International Association for the Study of Obesity. Circulation. 2009;120(16):1640-5.

34. Covidence. https://www.covidence.org. Accessed 14 March 2020

35. Armijo-Olivo S, Stiles CR, Hagen NA, Biondo PD, Cummings GG. Assessment of study quality for systematic reviews: a comparison of the Cochrane collaboration risk of bias tool and the effective public health practice project quality assessment tool: methodological research. J Eval Clin Pract. 2012;18(1):12-8.

36. Harrison S, Jones HE, Martin RM, Lewis SJ, Higgins JP. The albatross plot: a novel graphical tool for presenting results of diversely reported studies in a systematic review. Res Synth Methods. 2017;8(3):281-9.

37. Egger M, Smith GD, Schneider M, Minder C. Bias in meta-analysis detected by a simple, graphical test. Bmj. 1997;315(7109):629-34.

38. Ahrens W, Moreno L, Mårild S, Molnár D, Siani A, De Henauw S, et al. Metabolic syndrome in young children: definitions and results of the IDEFICS study. Int J Obes. 2014;38(S2):S4.

39. Haffner SM, Valdez RA, Hazuda HP, Mitchell BD, Morales PA, Stern MP. Prospective analysis of the insulin-resistance syndrome (syndrome $\mathrm{X}$ ). Diabetes. 1992;41(6):715-22.

40. Isomaa B, Almgren $\mathrm{P}$, Tuomi T, Forsén B, Lahti K, Nissén $\mathrm{M}$, et al. Cardiovascular morbidity and mortality associated with the metabolic syndrome. Diabetes Care. 2001;24(4):683-9.

41. Malik S, Wong ND, Franklin SS, Kamath TV, L'Italien GJ, Pio JR, et al. Impact of the metabolic syndrome on mortality from coronary heart disease, cardiovascular disease, and all causes in United States adults. Circulation. 2004;110(10):1245-50.

42. Lip G, Barnett A, Bradbury A, Cappuccio F, Gill P, Hughes E, et al. Ethnicity and cardiovascular disease prevention in the United Kingdom: a practical approach to management. J Hum Hypertens. 2007;21(3):183.

\section{Publisher's Note}

Springer Nature remains neutral with regard to jurisdictional claims in published maps and institutional affiliations.

Ready to submit your research? Choose BMC and benefit from:

- fast, convenient online submission

- thorough peer review by experienced researchers in your field

- rapid publication on acceptance

- support for research data, including large and complex data types

- gold Open Access which fosters wider collaboration and increased citations

- maximum visibility for your research: over $100 \mathrm{M}$ website views per year

At $\mathrm{BMC}$, research is always in progress.

Learn more biomedcentral.com/submission 